\title{
Artérias das glândulas adrenais em avestruzes (Struthio camelus)
}

\author{
Angelita das Graças de Oliveira Honorato ${ }^{1}$ \\ Cheston César Honorato Pereira ${ }^{2}$ \\ Juliana França Ortega ${ }^{1 *}$ \\ Rozana Cristina Arantes ${ }^{1}$ \\ Bruno Gomes Vasconcelos ${ }^{1}$ \\ Frederico Ozanam Carneiro e Silva ${ }^{1}$ \\ 'Faculdade de Medicina Veterinária da Universidade Federal de Uberlândia \\ Avenida Pará, 1720, Campus Umuarama, Bloco 2T, CEP 38400-902, Uberlândia - MG, Brasil \\ ${ }^{2}$ Faculdade de Medicina Veterinária da Universidade de Rio Verde, Rio Verde - GO, Brasil \\ *Autor para correspondência \\ julianafortega@gmail.com
}

Submetido em 03/04/2011

Aceito para publicação em 08/10/2011

\section{Resumo}

O crescimento da criação racional de avestruz e seus subprodutos têm despertado interesse dos pesquisadores em ampliar os estudos com esse animal. Assim, áreas de pesquisa básicas, como a morfologia, tornam-se necessárias para dar subsídios às áreas aplicadas. Com o intuito de contribuir com o conhecimento referente aos arranjos vasculares das glândulas adrenais, utilizaram-se 30 avestruzes (Struthio camelus), de quatro dias de vida, tendo seus contingentes arteriais marcados com solução aquosa corada de Neoprene Látex " 450 " a 50\% e fixados em solução diluída de formol a $10 \%$. A cavidade celomática foi exposta para a identificação das referidas glândulas, que são órgãos pares e encontram-se recobertas por tecido conjuntivo frouxo, disposto simetricamente nos dois antímeros, lateralmente à aorta descendente, caudalmente aos pulmões e cranio-medialmente aos lobos craniais dos rins. O aporte sanguíneo arterial, em ambos os antímeros, é proveniente das artérias adrenais direita e esquerda, dos ramos das artérias renais craniais direita e esquerda e dos ramos diretos da aorta descendente. Independentemente da origem, os números de ramos destinados às glândulas adrenais variaram de um a dois e de um a três respectivamente para os antímeros esquerdo e direito.

Palavras-chave: Aves, Morfologia, Vascularização

\section{Abstract}

Arteries of the adrenal glands in ostriches (Struthio camelus). The growth of rational ostrich breeding and their byproducts has attracted interest from researchers to increase the studies in this animal. Thus, basic research areas, such as morphology, become necessary to provide the applied areas with knowledge. Aiming to contribute to the knowledge on the vascular arrangements of the adrenal glands, 30 ostriches (Struthio camelus) were used, four days old, who had their arterial components marked with a 50\% stained aqueous solution of 
Neoprene Latex " 450 " and fixed in a 10\% diluted solution of formaldehyde. The coelomic cavity was exposed for identifying these glands, which are paired organs that are covered by loose connective tissue, symmetrically arranged in the two antimeres, laterally to the descending aorta, caudally to the lungs, and cranio-medially to the cranial lobes of the kidneys. The arterial blood supply, in both antimeres, is derived from the right and left adrenal arteries, the right and left cranial renal artery branches, and the right branches of the descending aorta. Regardless of the origin, the number of branches going to the adrenal glands ranged from one to two and one to three respectively, in the left and right antimeres.

Key words: Birds, Morphology, Vascularization

\section{Introdução}

A avestruz é uma ave originária da África do Sul, onde atualmente encontra-se localizado o maior plantel do mundo, seguido pelos Estados Unidos, Austrália e Canadá (MARINHO et al., 2004). Pertence à ordem Struthioniformes e faz parte do grupo das ratitas (Ratitae), palavra derivada do latim "ratis", desprovido de quilha, não tendo, portanto, capacidade de vôo. Apresentam características anatômicas e morfológicas diferentes em relação às aves domésticas e silvestres. $\mathrm{O}$ corpo tem forma ovalada e está recoberto por penas e plumas. Vivem cerca de 60 a 70 anos, podendo chegar a 80 na região da África do Sul (CARRER et al., 2004).

A criação racional de avestruzes tem despertado enorme interesse de mercado devido à possibilidade da realização de um novo investimento com boas taxas de retorno. Tem alcançado patamares de rentabilidade expressivos e agregado valor em seus produtos e subprodutos de maneira diferenciada. Entretanto, não se deve superestimar sua capacidade de retorno econômico, baseando-se sempre em experiências concretas (KORNFELD et al., 2001). Assim, o aprimoramento e manutenção da qualidade das raças, como os que envolvem as epidemiologias das doenças infecciosas, as anomalias congênitas e os problemas ligados à imunização necessitam de conhecimento morfofisiológico das estruturas envolvidas (SILVA et al., 1997).

Glândulas adrenais são órgãos responsáveis pela secreção de hormônios, tais como os mineralocorticóides, glicocorticóides, esteróides sexuais, que por sua vez, têm a capacidade de ativar o sistema imune destes animais (AMARAL et al., 2004). As glândulas adrenais em galinhas da linhagem NPK são estruturas com formato aproximado de um triângulo escaleno, com colorações amarronzadas, encontradas cranialmente ao lobo cranial do rim (AMARAL et al., 2004). No entanto, Koch (1973) identificou as glândulas adrenais em galinhas como estruturas cilíndricas, de coloração marrom-amarelo e, encontradas medialmente ao pólo cranial do lobo cranial do rim.

De acordo com Baumel (1986), são formadas por um par de glândulas dispostas paralelamente em cada antímero, na maioria das aves. Em algumas exceções, como a espécie Sula variegata e Larus argentatus, estão fundidas ao nível do plano sagital mediano e sua vascularização é realizada pela artéria adrenal, ramo da artéria renal cranial. Siller e Hindle (1969) citam que as artérias renais esquerda e direita surgem em regiões paralelas e imediatamente emitem um ou mais ramos para glândula adrenal, que posteriormente vão ser chamadas de artérias adrenais. Amaral et al. (2004) ressaltaram grande generalidade com relação à irrigação da glândula adrenal e uma escassez de dados precisos, principalmente sobre os aspectos topográficos das mesmas, necessitando de uma especificidade quanto à diferenciação dos tipos de vasos que irrigam a glândula adrenal.

Devido à escassez de informações sobre a vascularização das glândulas adrenais nestas aves e diante à necessidade de se pesquisar o aporte de sangue oxigenado para estes órgãos, fundamentais na homeostase do organismo, objetivou-se descrever o suprimento arterial para a glândula adrenal em avestruzes.

\section{Material e Métodos}

Utilizaram-se 30 avestruzes (Struthio camelus), machos e fêmeas, com até quatro dias de idade, procedentes de criatórios de Uberlândia - MG, após 
mortes naturais. $\mathrm{O}$ estudo foi realizado no laboratório de anatomia veterinária da Universidade Federal de Uberlândia.

Para o preparo dos animais, foi feita uma abertura na cavidade torácica na região do nono espaço intercostal localizando-se a aorta descendente. Então, fez-se uma incisão neste vaso e com auxílio de uma cânula injetouse uma solução corada de Neoprene Látex “450” a 50\% (Du Pont do Brasil - Indústrias Químicas). A seguir, as aves foram fixadas com solução de formol a $10 \%$ que foi injetada utilizando-se uma seringa por via intramuscular profunda, subcutânea e intracavitária, e depois foram submersas na mesma solução por um período mínimo de $48 \mathrm{~h}$.

A cavidade celomática foi aberta e dissecada para identificar as glândulas adrenais e descrever sua vascularização. A dissecação foi acompanhada pelo registro em fotografia (câmera digital Sony DSC-W35) e auxilio da Nomina anatômica avium (BAUMEL, 1979) para descrição dos termos. Utilizou-se a estatística descritiva para ordenação dos dados.

\section{Resultados}

Em todos os casos, a glândula adrenal direita está localizada cranialmente em relação à esquerda, crâniomedial aos lobos craniais dos rins, colateralmente à aorta descendente e caudalmente aos pulmões. As glândulas adrenais, direita e esquerda, são irrigadas principalmente pelas artérias adrenais, que são ramos das respectivas artérias renais craniais, e ramos direto da artéria aorta descendente. A referida glândula está recoberta por tecido conjuntivo frouxo, é de morfologia alongada e coloração marrom. Independentemente da origem, o número de ramos destinado às glândulas adrenais variou de um a dois no antímero esquerdo e de um ou três para o direito (Figura 1).

No antímero direito, ambas as artérias contribuíram em dois casos em comum, para irrigação da glândula. Tanto a artéria adrenal como a aorta descendente contribuíram com a emissão de um ramo vascular comum em uma ave $(3,3 \%)$ e a distribuição concomitante de um ramo da artéria adrenal e dois ramos da aorta descendente

FIGURA 1: Fotografia e esquema dos ramos oriundos da aorta descendente (setas) para a glândula adrenal de avestruzes (Struthio camelus). AD = Glândula adrenal direita; $\mathrm{AE}=$ Glândula adrenal esquerda; 1 = Aorta descendente.

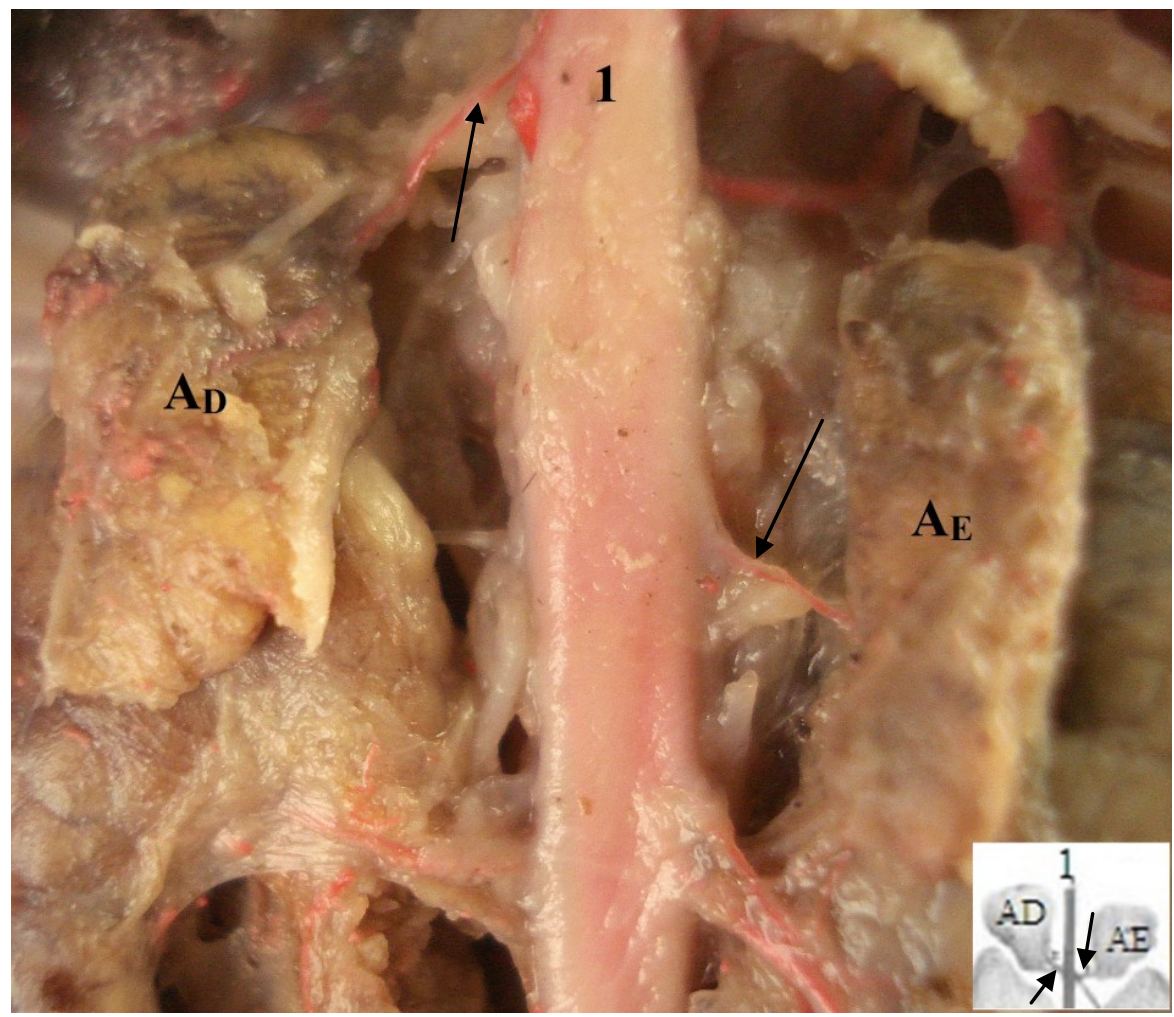


em um caso (3,3\%). A artéria adrenal direita emitiu um ramo em 12 aves (40\%), dois ramos em duas $(6,6 \%)$ e três ramos em outras duas (6,6\%). A contribuição desta artéria se dá em 16 casos (53,3\%) estudados, no antímero direito. A aorta descendente emitiu um ramo em 13 casos $(43,3 \%)$ e dois ramos em um $(3,3 \%)$, dando a sua contribuição em 14 aves (46,6\%).

Já no antímero esquerdo a artéria adrenal dá a sua contribuição em 13 casos (43,3\%) e a aorta descendente em 17 casos $(56,6 \%)$. Enquanto a artéria adrenal emitiu um ramo em 13 aves (43,3\%), a aorta descendente com um ramo em $16(53,3 \%)$ e dois ramos em uma ave (3,3\%), não observando assim a contribuição simultânea das duas artérias para este antímero. Sendo assim, a Figura 1 demonstra a maior incidência das artérias que irrigam a glândula adrenal, que no caso foram ramos oriundos diretamente da aorta descendente para suprir exclusivamente o órgão em questão.

\section{Discussão}

As avestruzes estudadas apresentaram um par de glândulas adrenais, dispostas paralelamente, na cavidade peritoneal, colateralmente à aorta descendente, caudalmente aos pulmões e crânio-medialmente aos lobos craniais dos rins, concordando parcialmente com o citado por Dyce et al. (1987), nos quais a referida estrutura localizou-se no pólo cranial do rim colateralmente, sem informar precisamente a localização desta estrutura.

A localização na cavidade abdominal e o paralelismo nos dois antímeros foram citados por Baumel (1986) em aves, o qual também revela que espécimes como Sula variegata (alcatraz piqueiro) e Larus argentatus (gaivota prateada) apresentam as glândulas fundidas no nível do plano sagital mediano, tal afirmação não foi observada em Struthio camelus. Já a localização caudal aos pulmões observada neste estudo esteve em concordância com Venzke (1986), que ressaltou ainda a topografia no pólo cranial dos rins, desde fusionada, alongada, piramidais ou ovais até uma estruturação irregular. Nesta pesquisa observaram-se as formas triangulares alongadas ou irregulares.
Em observações realizadas por Baumel (1986) e Venzke (1986) com galinhas, notou-se que somente a artéria renal cranial promove o suprimento arterial das glândulas adrenais, enquanto neste estudo encontrou-se a irrigação destes órgãos através de ramos diretos da artéria aorta descendente e ramos das artérias renais craniais direita e esquerda, denominada de artéria adrenal.

Baumel (1986) citou em seus estudos que as artérias renais craniais suprem as glândulas adrenais e as gônadas, sendo que segmento de cada artéria renal cranial emite cranialmente uma ou mais artérias adrenais. Concordando com o autor, neste estudo ainda observouse a presença de suprimento arterial para a glândula provindo diretamente da aorta descendente. Já Amaral et al. (2004) relataram que em galinhas a irrigação para estes órgãos era de ramos diretos oriundos das artérias adrenais direita e esquerda e aorta descendente, notou ainda, o entrecruzamento de artérias entre os antímeros, fato este não observado com Struthio camelus.

A partir dos resultados foi possível concluir que as glândulas adrenais de avestruzes (Struthio camelus) são irrigadas pelas artérias adrenais provenientes das renais craniais e por ramos diretos da aorta descendente.

\section{Referências}

AMARAL, V. C.; SANTANA, M. I.; BOMBONATO, P. P.; SILVA, F. O. C.; BENEDICTO, H. G. Vascularização das glândulas adrenais em galinhas da linhagem NPK (Gallus gallus domesticus). Brazilian Journal of Veterinary Research and Animal Science, São Paulo, v. 41, n. 6, p. 361-367, 2004.

BAUMEL, J. J. Nomina anatômica avium. London: Academic Press, 1979. 779 p.

BAUMEL, J. J. Coração e vasos sanguíneos das aves. In: GETTY, R. (Ed.). Anatomia dos animais domésticos. v. 2. 5. ed. Rio de Janeiro: Guanabara, 1986. p. 1842-1880.

CARRER, C. C.; ELMÔR, R. A.; KONFELD, M. E.; CARVALHO, M. C. A criação de avestruz: Guia completo de A a Z. Pirassununga: C. C. Carrer, 2004. 255 p.

DYCE, K. M.; SACK, W. O.; WENSING, C. J. G. Anatomia das aves. In: DYCE, K. M.; SACK, W. O.; WENSING, C. J. G. (Ed.). Tratado de anatomia veterinária. Rio de Janeiro: Elsevier, 1987. p. 773-798.

$\mathrm{KOCH}, \mathrm{T}$. Anatomy of the chicken and domestic birds. Ames: The Iowa State University Press, 1973. 170 p.

KORNFELD, M. E.; ELMÔR, R. A.; CARRER, C. C. Avestruzes no Brasil: incubação e criação de filhotes. Pirassununga: Brasil Ostrich, 2001. 122 p. 
MARINHO, M.; MEIRELlES, M. V.; SOUZA, A. V. G. Determinação da microflora do trato gastrointestinal de avestruzes (Struthio Camelus) criados na região noroeste do estado de São Paulo, submetidos à necropsia. Arquivos do Instituto Biológico, São Paulo, v. 71, n. 3, p. 267-271, 2004.

SILVA, F. O. C.; SEVERINO, R. S.; SANTOS, A. L. Q.; DRUMMOND, S. S.; BOMBONATO, P. P.; SANTANA, M. I. S.; GONÇALEZ, P. O.; MARÇAL, A. V. Vascularização arterial da bolsa cloacal em Gallus gallus domesticus (Linhagem Ross). Revista da Faculdade de Zootecnia, Veterinária e Agronomia de Uruguaiana, Uruguaiana, v. 4, n. 1, p. 67-74, 1997.
SILLER, W. G.; HINDLE, R. M. The arterial blood supply to the kidney of the fowl. Journal of Anatomy, London, v. 104, n. 1, p. 117-135, 1969.

VENZKE, W. G. Endocrinologia das aves. In: GETTY, R. (Ed.). Anatomia dos animais domésticos. Vol. 2. 5. ed. Rio de Janeiro: Guanabara, 1986. p. 1840-1841. 